Copyright (C 2014 IEEE. Personal use of this material is permitted. Permission from IEEE must be obtained for all other uses, in any current or future media, including reprinting/republishing this material for advertising or promotional purposes, creating new collective works, for resale or redistribution to servers or lists, or reuse of any copyrighted component of this work in other works. 


\section{Design and Modeling of a Hundred Percent Renewable Energy Based Suburban Utility}

\author{
Shaji V Mathews \\ Department of Electrical and \\ Computer Engineering \\ Curtin University of Technology \\ Perth, Australia \\ Email: shaji@aicaengineering.com
}

\author{
Sumedha Rajakaruna \\ Department of Electrical and \\ Computer Engineering \\ Curtin University of Technology \\ Perth, Australia \\ Email: s.rajakaruna@curtin.edu.au
}

\author{
C. V. Nayar \\ Regen Power Pty Ltd \\ Perth, Australia \\ Email: c.v.nayar@regenpower.com
}

\begin{abstract}
This paper presents the complete system modelling, designing and controlling of an islanded minigrid power supply to the town of Carnarvon, Western Australia. Carnarvon power system is an isolated network supplying power to approximately 5000 people via $205 \mathrm{~km}$ of distribution lines. The existing power system is supplied by a number of large centralized $21 \mathrm{MW}$ Diesel Generators. The objective of this paper is to report the design, development and installation of a Photovoltaic (PV) diesel hybrid-power system such that the operating cost can be minimized and the load on the aging generators could be significantly reduced. The proposal includes the installation of two $25 \mathrm{~kW}$ DC variable speed diesel generators and a suitably sized advanced battery bank at each suburban transformer to ensure hundred percent penetration of solar power by residential customers in the local area. This method of control is modelled and simulated in HOMER, PSpice and Matlab. The different modes of control used to integrate maximum solar energy, reduce diesel consumption and also the methodology imposed to store excess renewable energy for operation during the night.
\end{abstract}

Keywords- Hybrid system, Renewable energy, Variable speed generator, remote, Carnarvon, Ultrabattery.

\section{INTRODUCTION}

The case study in this paper is based on the extensive penetration of PV into Carnarvon, Western Australia. Carnarvon is a coastal town situated approximately 900 kilometres north of Perth, Western Australia. It lies at the mouth of the Gascoyne River on the Indian Ocean. The popular Shark Bay world heritage area lies to the south of the town and the Ningaloo Reef lies to the north. At the 2011 census, Carnarvon had a population of 4,559 [1].

Horizon Power is operating over 30 isolated power systems ranging from hundreds of $\mathrm{kW}$ to tens of $\mathrm{MW}$ in generating capacity. These multiple unit fossil fuel based generation systems are expensive to run and have a large carbon footprint. Integrating renewable energy generation into these power systems is thus necessary considering its values in economic, environment and social benefits.

Carnarvon has a warm semi-arid climate with occasional tropical cyclones effecting during the summer months bringing heavy rain and strong winds. Apart from this erratic source of rainfall summers are normally dry. Temperatures range from an average maximum of $33^{\circ} \mathrm{C}$ in February to $22^{\circ} \mathrm{C}$ in July; average minimums are $23^{\circ} \mathrm{C}$ and $11^{\circ} \mathrm{C}$ respectively. Such temperatures made Carnarvon an ideal place for Solar PV installations.

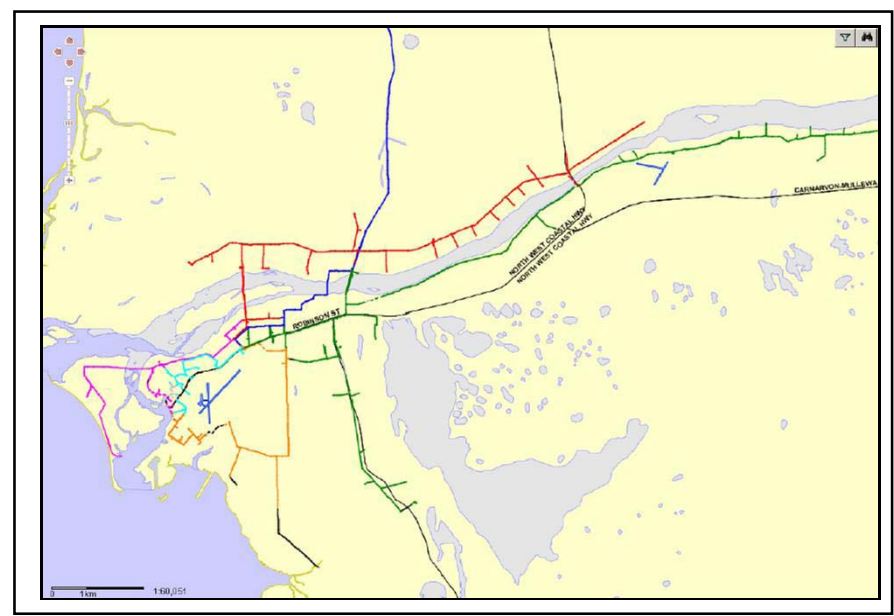

Figure 1: Carnarvon location map [1]

\section{POWER DEMAND ANALYSIS}

The Carnarvon distribution network is an isolated gas/diesel generation grid with a more than 13 percentage of embedded PV systems. This is primarily radial in nature with some long rural feeders, and covers around $200 \mathrm{~km}$ of overhead lines servicing approximately 5300 general public. The peak system load to date is $11600 \mathrm{~kW}$ and the average system midday loads are approximately $6800 \mathrm{~kW}$ in summer and $5000 \mathrm{~kW}$ in winter, $60 \%$ of the peak demand is from commercial/industrial loads with the remaining $40 \%$ resulting from residential loads.

The power station in Carnarvon is also owned and operated by Horizon Power and comprises 13 generator sets which are predominantly dual fuelled by gas and diesel and 
have a nominal rating of $22100 \mathrm{~kW}$ which is derated to $15900 \mathrm{~kW}$ in summer. The generator sets make, quantity and ratings provided on table 1 . The generating strategy in Carnarvon is to operate with enough spinning reserve to cover the loss the largest online generator. This also sets the limit for the amount of distributed PV in the town given the concern that some power system events might see all PV disconnect from the system at the same time when generating at maximum output.

\begin{tabular}{|c|r|r|r|}
\hline $\begin{array}{c}\text { Generator Set } \\
\text { Description }\end{array}$ & Quantity & $\begin{array}{c}\text { Nominal } \\
\text { rating } \\
(\mathrm{kWp})\end{array}$ & $\begin{array}{c}\text { Summer } \\
\text { rating } \\
\text { level } \\
(\mathrm{kWp})\end{array}$ \\
\hline Cummins & 5 & 1120 & 800 \\
\hline Detroit & 1 & 1200 & 800 \\
\hline Wartsila & 3 & 2340 & 1500 \\
\hline Allen GBC- & 1 & 1200 & 1200 \\
\hline Mirrlees & 1 & 2240 & 1800 \\
\hline Mirrlees KP8- & 1 & 2500 & 1800 \\
\hline Mirrlees KP8- & 1 & 2305 & 1800 \\
\hline Totals & 13 & 22065 & 15900 \\
\hline
\end{tabular}

Table 1: Generator set description [1]

This PV penetration is coupled with a strong solar resource of an average daily solar insolation of $6.2 \mathrm{kWh} / \mathrm{m} 2[2]$. Figure 2 shows the radiation data of Carnarvon. PV penetration is estimated to peak at $13 \%$ of system load at midday in both summer and winter. Consequently, impacts on the distribution network due to PV systems are starting to emerge. In 2011 the concerns about these impacts were sufficient enough for Horizon Power, the utility that owns and operates the Carnarvon distribution network, to apply a limit of $1.15 \mathrm{MWp}$ of distributed PV system capacity on the distribution network.

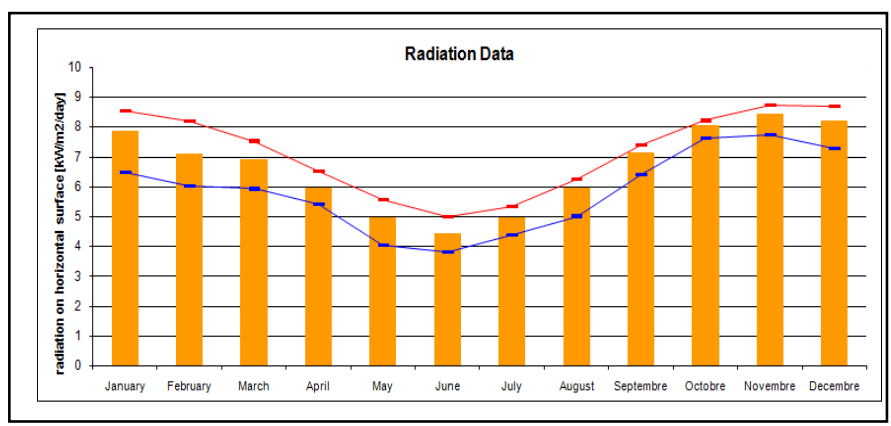

Figure 2: Radiation data

As per the 2011 report there is $1090 \mathrm{kWp}$ of nominal PV capacity connected to the distribution network. The average size of a PV system connected to the distribution network is $8.30 \mathrm{kWp}$. The PV distribution in Carnarvon is also quite clustered with one medium voltage feeder loaded to $39 \%$ of its average midday load and distribution transformers loaded up to $70 \%$ of the rated capacity of the transformer.

\section{A. Load Profile}

The Load Profile given below in Figure 3 outlines the average summer peak day, average summer day and summer estimated system PV generation. Also Figure 4 outlines the average winter peak day, average winter day and winter estimated system PV generation based on earlier report.

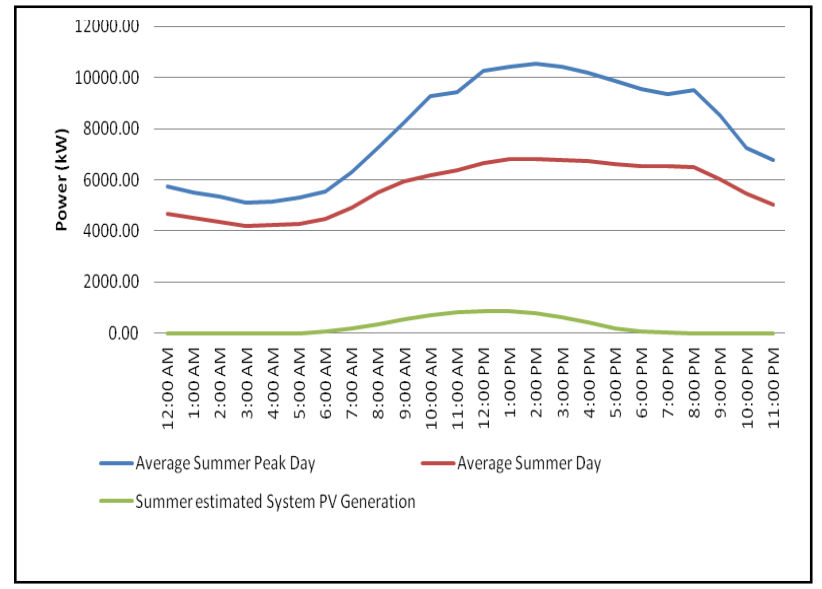

Figure 3: Carnarvon average and peak load profile in summer [1]

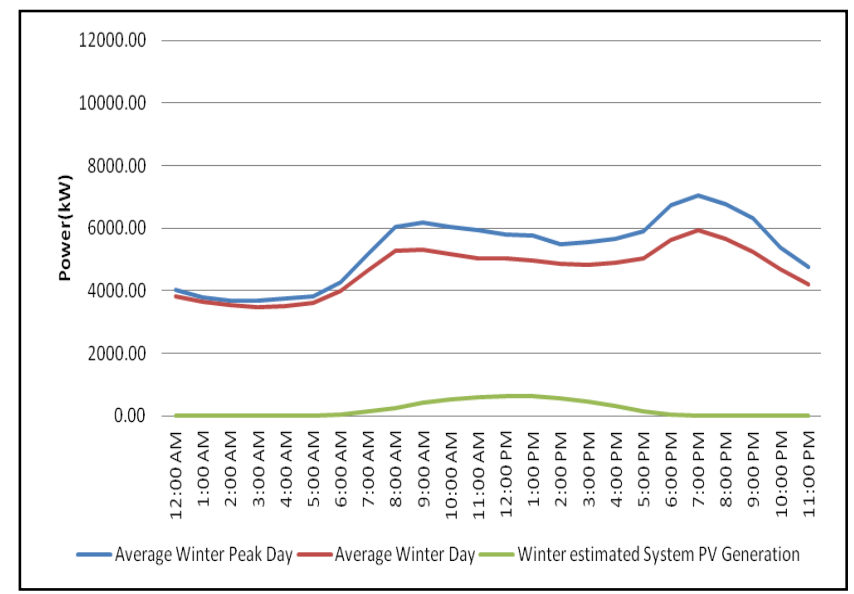

Figure 4: Carnarvon average and peak load profile in winter [1]

The distribution transformers loaded unequal PV system distribution than the $22 \mathrm{kV}$ feeders. The most highly loaded 15 distribution transformers are shown in Table 3 below the remaining transformers have a penetration less than $10 \%$. PV penetration on the Gibson has been shown to be high enough to cause back feeding to the $22 \mathrm{kV}$ network. Since there was no storage facility available in that transformer, the excess energy has to go through the transformer and it may not good for the uninterrupted performance of the network and this can create blackout. 
Table 2: Carnarvon Distribution Transformers [1]

\begin{tabular}{|c|c|c|c|}
\hline $\begin{array}{c}\text { Distribution } \\
\text { Transformer }\end{array}$ & $\begin{array}{c}\text { Transfo } \\
\text { rmer } \\
\text { Rating } \\
\text { KVA }\end{array}$ & $\begin{array}{c}\text { PV } \\
\text { System } \\
\text { nominal } \\
\text { capacity } \\
(\mathrm{kWp})\end{array}$ & $\begin{array}{c}\text { PV Capacity } \\
\text { as a \% of } \\
\text { Transformer } \\
\text { Capacity }\end{array}$ \\
\hline GIBSON & 315 & 221 & $70 \%$ \\
\hline NR122/6 & 63 & 40 & $63 \%$ \\
\hline NR67/17/106 & 50 & 26 & $53 \%$ \\
\hline NR129 & 63 & 30 & $48 \%$ \\
\hline NR67/17/18 & 100 & 40 & $40 \%$ \\
\hline BILCICH & 63 & 20 & $32 \%$ \\
\hline PONY CLUB & 200 & 60 & $30 \%$ \\
\hline NR90A/4 & 100 & 29 & $29 \%$ \\
\hline FINNERTY & 100 & 29 & $29 \%$ \\
\hline CHRISTIAN & 100 & 21 & $21 \%$ \\
\hline SCHOOL & 200 & 35 & $17 \%$ \\
\hline RICHARDSON & 200 & 30 & $15 \%$ \\
\hline NELSON & 200 & 30 & $15 \%$ \\
\hline ANGELO N & 200 & 12 & $12 \%$ \\
\hline SILVER CITY & 100 & 20 & $10 \%$ \\
\hline MUNGULLAH & 200 & & \\
\hline
\end{tabular}

\section{SYSTEM DESCRIPTION}

The Carnarvon distribution network is primarily radial in nature with some long rural feeders, and comprises in total of some $200 \mathrm{~km}$ of overhead lines servicing approximately 5300 people. The peak system load to date is $11600 \mathrm{~kW}$ and the average system midday loads are approximately $6800 \mathrm{~kW}$ in summer and $5000 \mathrm{~kW}$ in winter, $60 \%$ of the peak demand is from commercial/industrial loads with the remaining $40 \%$ resulting from residential loads.

The generating strategy in Carnarvon is to operate with enough spinning reserve to cover the loss the largest online generator. This also sets the limit for the amount of distributed $\mathrm{PV}$ in the town given the concern that some power system events might see all PV disconnect from the system at the same time when generating at maximum output.

The aim of this paper to model a Photovoltaic (PV) diesel hybrid-power system such that the operating cost can be minimized and the load on the aging generators could be significantly reduced. The proposal includes the installation of two $25 \mathrm{~kW}$ DC variable speed diesel generators and a suitably sized advanced battery bank at each suburban transformer to ensure hundred percent penetration of solar power by residential customers in the local area. Figure 5 shows the schematic diagram of the proposed system.

Figure 6 shows the comparison graph of the ultrabattery VRLA against AGM VRLA battery. It clearly shows that ultrabattery has the highest Partial State of Charge (HRPSoC) cycle numbers.

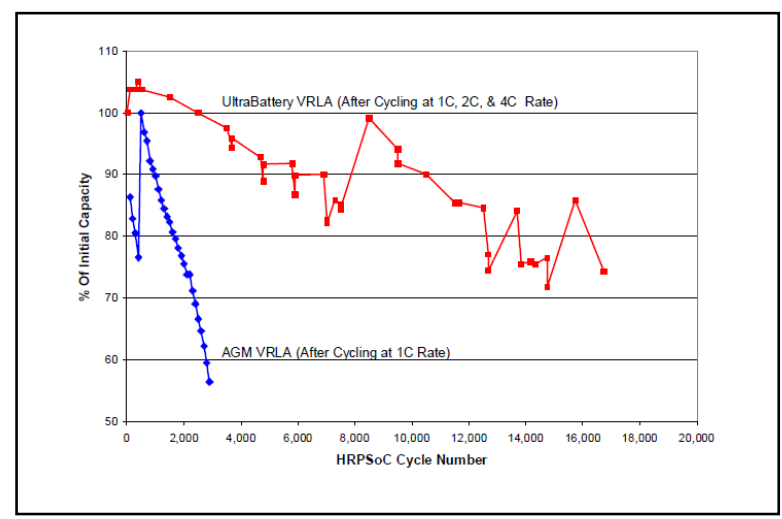

Figure 6: Ultrabattery HRPSoC Utility Cycle Aging Effect Between 2,500 and 16,740 Cycles, At 1C 1 Rate for 6 min [3]

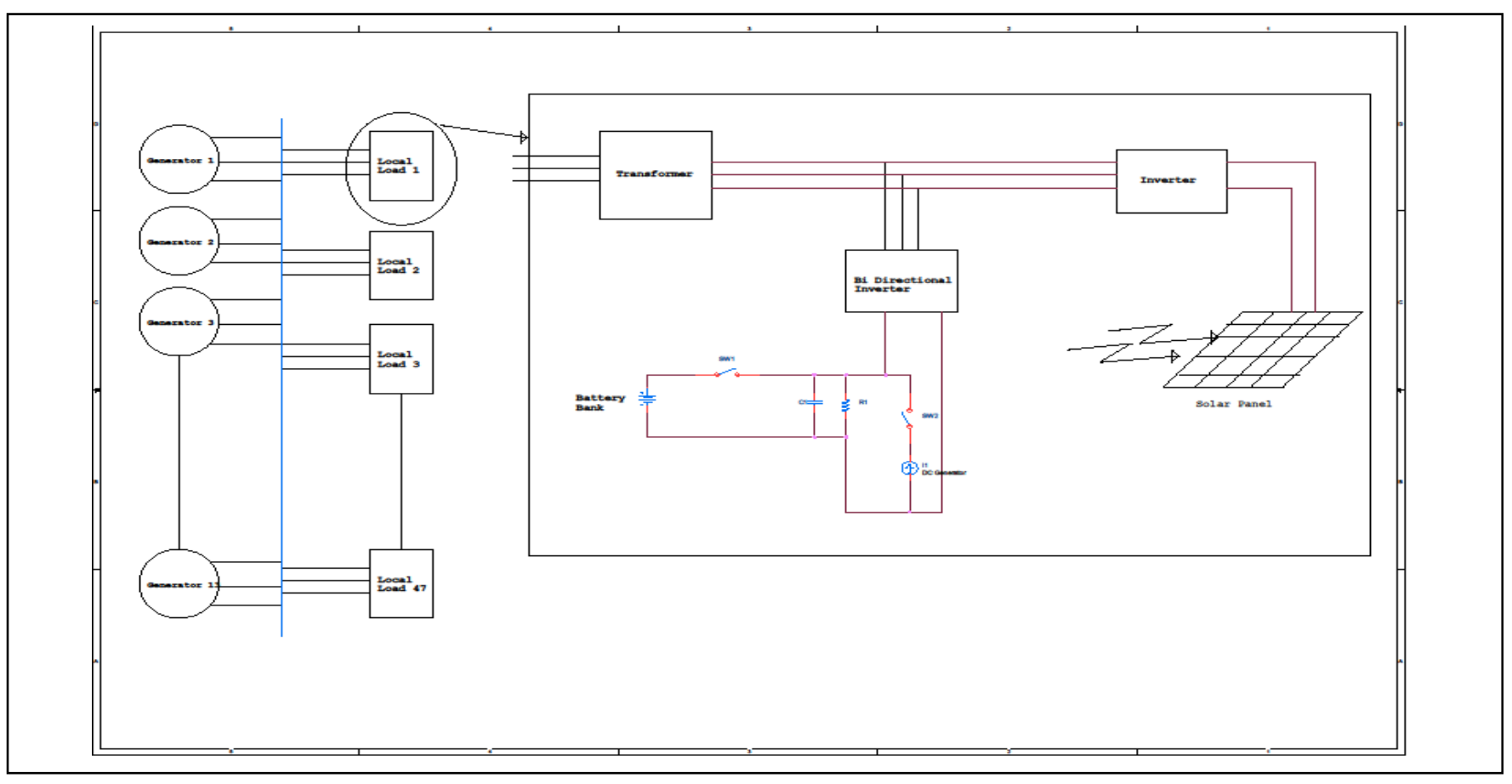

Figure 5: Schematic diagram of the proposed system 


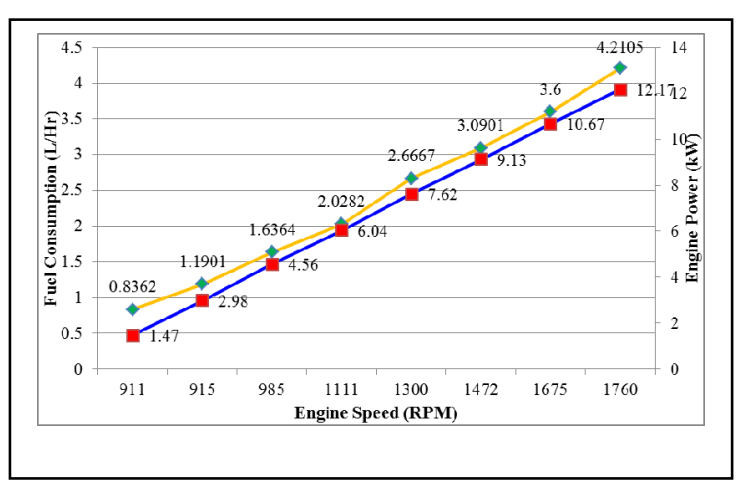

Figure 7: Typical fuel efficiency curve of a diesel engine in variable speed and Constant speed

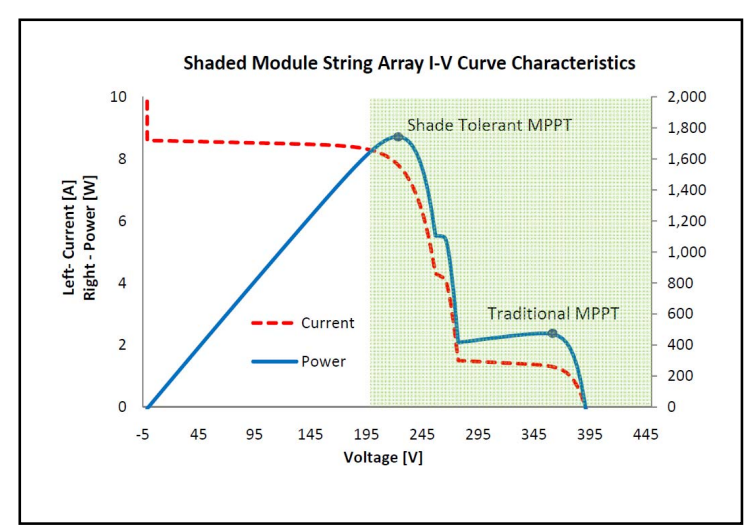

Figure 8: Shaded Array String I-V curve [4]

Fuel efficiency and output power curve for a diesel engine in variable speed is presented in Figure 7. When operating at a variable speed, the engine requires only approximately $4 \mathrm{~L}$ per hour to produce around $12.5 \mathrm{~kW}$ of power, actually the minimum fuel level. Figure 8 shows shaded array string I-V curve of a newly developed shade tolerant maximum power point tracker (MPPT) inverter.

\section{SyStem STRUCTURE AND MODELLing}

Although diesel generators are typically reliable, they have high operational cost and require substantial maintenance. So, the combination with the renewable energy power generation will benefit remote areas power supply, point to the technology's economic and reliability benefits [5].

The main role of the remote area power system is to harness maximum renewable energy sources. In nature, renewable energy sources are uncontrolled and intermittent. Therefore, they need to operate parallel with diesel generator or battery bank. However, this parallel operation in many cases cause the conventional diesel generators to operate in low efficiency due to low load or high penetration of renewable energy sources. The use of VSDG and optimized battery bank may alleviate this problem.

The proposed system has been modelled in the following software to select best components and cost-effective components and size.

\section{Proposed System Modelling and optimisation}

\section{a) Homer Modeling}

The well-known Homer software was used to optimize the best possible options by varying constraints to optimize small power systems to give the best options for modelling and investigations [6].

The program first runs an hourly simulation of all possible configurations of system types. The load efficiency of diesel generators including lower efficiency, when not fully operating can be determined. Analysis is repeated to optimize various user-defined factors, such as fuel price, load size, reliability requirement, and resource quality.

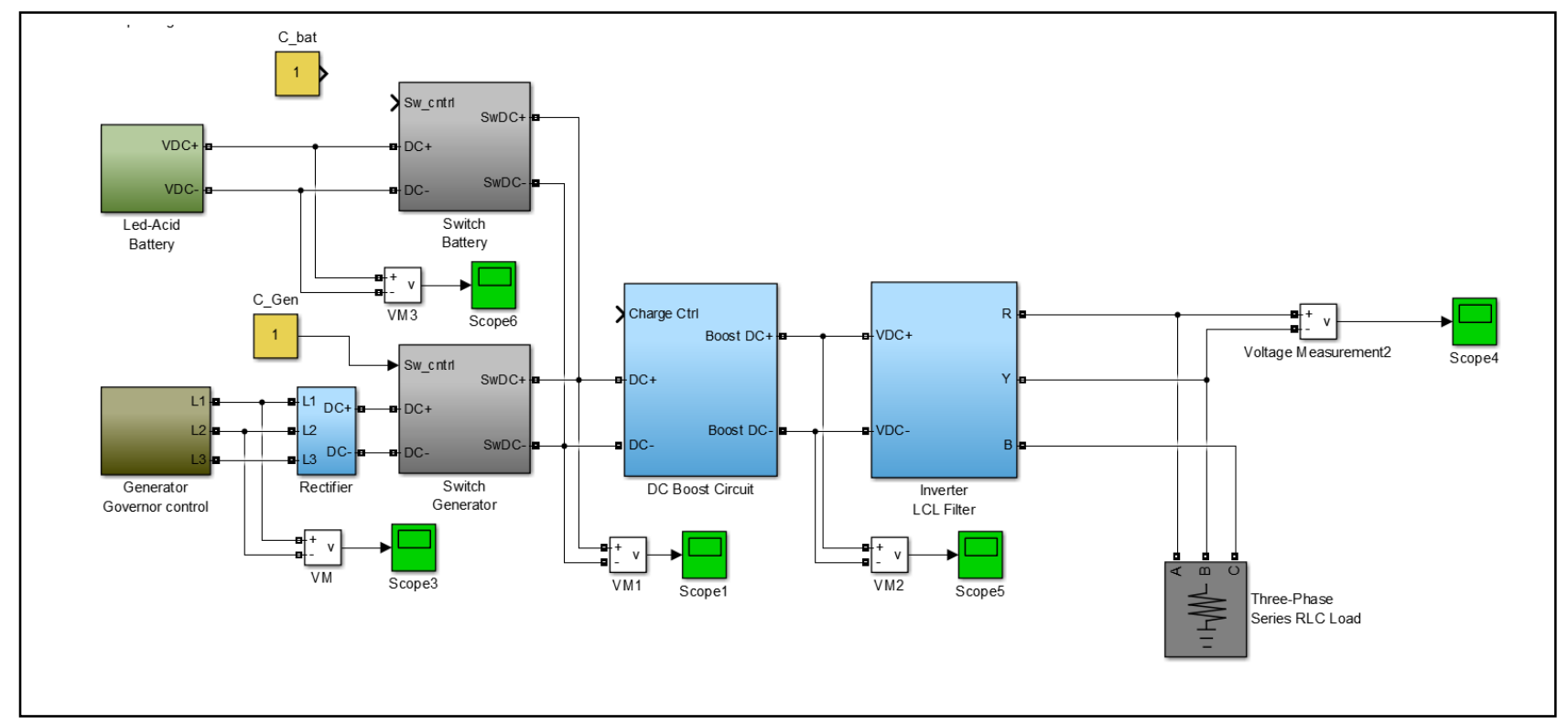




\section{b) PSpice Modeling}

PSpice modelling was used to analyse time domain response, small signal frequency response, total power dissipation, transient analysis and transfer functions [7].

The types of analysis used are:

- DC Analysis which is used for circuits with time, by calculating nodal voltages and branch current or a range of values

- Transient Analysis is used with variant sources to calculate all nodes voltage and branch currents over a time interval.

- AC Analysis is used for signal analysis of all circuits with varying frequencies and it calculates all nodal voltage and branch currents over a range of frequencies.

\section{c) Matlab Modeling}

Matlab modelling is an efficient and cost effective way to analyse and implement a project with minimal errors and drawbacks. It can represent key aspects of the system including its requirements, its components and how those components communicate with each other [8].

The specialty of this software is that it can reference models and break up the hierarchy into separate models. It can also be broken down to facilitate individual modelling of the components.

\section{Modelling System Components}

High renewable energy penetration can make a real difference in the transition to renewable energy-based consumption with economical, safe, and environmentally sound energy storage solutions and backup systems. Offgrid or remote area applications, in which a relatively small amount of electricity storage has a big impact, such as controlling seconds to minutes of short-term power variability. In these situations, we can use the breakthrough capabilities of variable speed diesel generator and high quality energy storage to deliver solutions that make immediate and effective economic sense.

Following are the major components selected to integrate renewable energy into grid.

\section{a) Solar Modules}

Solar Modules, or Photovoltaic panels (PV), can be installed on the roofs of residential and commercial buildings and/or near each suburban transformer as required and can be integrated into the system by AC coupling.

\section{b) Batteries}

The newly developed UltraBattery technology performance enhancing features that exploit the performance benefits of the Partial State of Charge (PSoC) band, while mitigating the deteriorating effects of conventional lead-acid technology. This technology avoids the upper and lower bands of charge in its normal operation, therefore improving efficiency and battery life [9].

c) Inverters

There are two types of inverters; the island type that controls the batteries and provides the start and stop signals for the generators and maintain grid voltage and frequency also reactive power, and the grid type inverters that will converter distributed solar PV DC power into AC and directly feed to load and remaining going to battery through bidirectional inverter.

\section{d) Generators}

A Conventional fossil fuel based generators are designed to produce electricity at a fixed frequency which is rotating at a constant speed regardless of the power demand. Research in [10] and [11] shows that fuel consumption of a VSG is actually lower than the CSG during light load operation. This is an important characteristic of a fossil fuel based generator if fuel savings and the $\mathrm{CO} 2$ emissions reduction are the main concerns in the operation of a HPS. The fossil fuel based

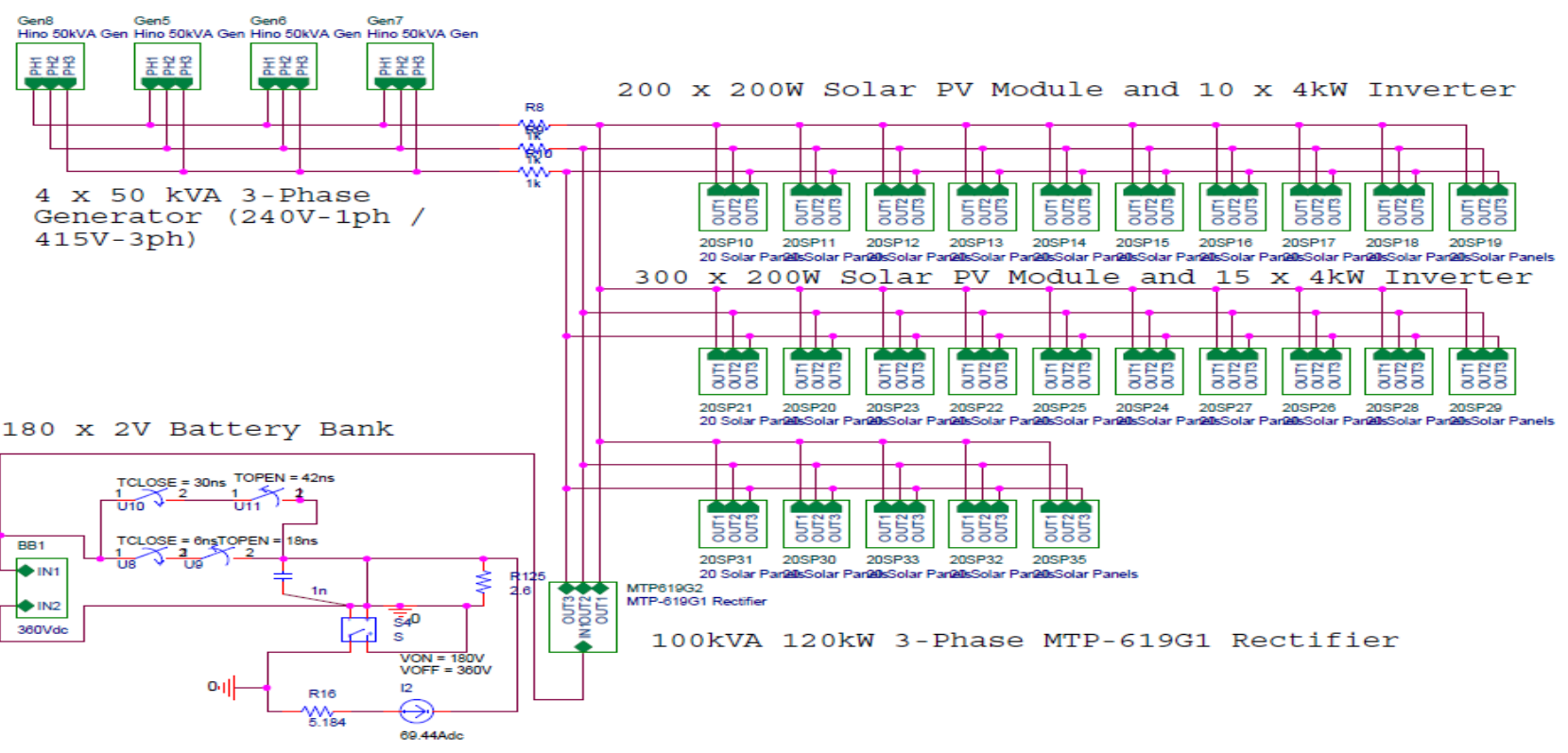


generators are modelled using the fuel consumption versus loading power characteristics. It is worth noting that, in HOMER the fuel load characteristic of a fuel-powered generator is assumed to be linear. This approximation may not be suitable table for the variable speed generator as its characteristic can be approximated as a polynomial curve that signifies lower fuel consumption for the operation below rated power [12].

There are two operating conditions of a fossil fuel based generator. During a deficit of renewable sources, the generator and battery bank power supply have to match the load demand. Alternatively, the generator power can charge the battery and supply the load demand simultaneously during light load demand. ,

System modelled in Matlab and PSpice as described. Figure 9 shows the simulation of Lead acid battery, variable speed diesel generator integrated with network through bidirectional inverter. In this system AC coupled distributed solar PV can be integrate as required for each suburban transformer. Figure 10 shows PSpice simulation, in that all existing generators, network and proposed components are modelled.

\section{SIMULATION RESULT}

Generator simulation was performed independent of the integrated system due to the dynamics of a diesel generator in Simulink model. An extended period of time would be required for simulation of a diesel generator because the machine takes approximately 4 seconds to stabilise, which is in contrast to the $1 \mu$ second of discrete time required by a PV cell, solar inverter, battery, or bi-directional inverter.

The following are the systems integrated for simulations:

$$
\begin{array}{ll}
\text { - } & \text { PV array } \\
\text { - } & \text { Solar inverter } \\
\text { - } & \text { Lead-acid battery } \\
\text { - } & \text { DC boost circuit } \\
\hline & \text { Bi-directional inverter }
\end{array}
$$

The result mainly describes the state of charge of the battery control and a variable speed generator, running times are explained and simulation results provided:

\section{a) SOC battery control:}

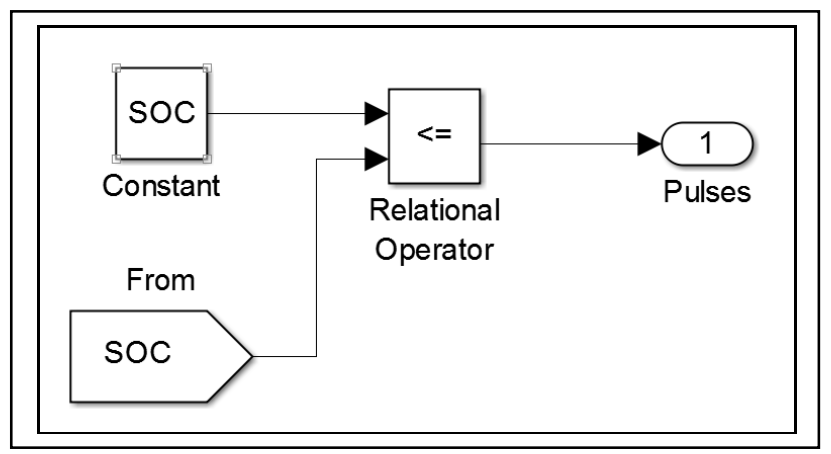

Figure 11: Instantaneous rotor and stator current during sub

$$
\text { nstantaneous rotor and stator current during sub }
$$

When the battery SOC reaches the target value, the switch connected to the boost converter and the bi-directional inverter will be disabled, which will disconnect the battery connection to load. In this case the diesel generator will be charging the battery.

\section{b) Battery charge control:}

Figure 11 shows the charge control, when the battery SOC is less than the specified level. The charge control will be activated and enable the IGBT connected across the boost converter diode. Pulses to boost IGBT are disabled in this situation. In this mode the DC-DC converter will be operating in Buck mode. Figure 12 shows the DC variable speed generator output.

When there is excess solar power the battery is charged through the charge control. The charge control output is in turn connected to the current controller. Figure 13 shows the battery bank state of charge. The battery will be charged at a constant 30Amps.

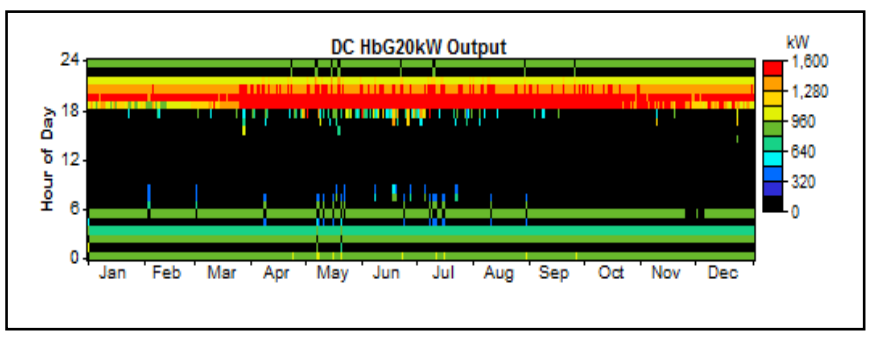

Figure 12: DC variable speed generator output

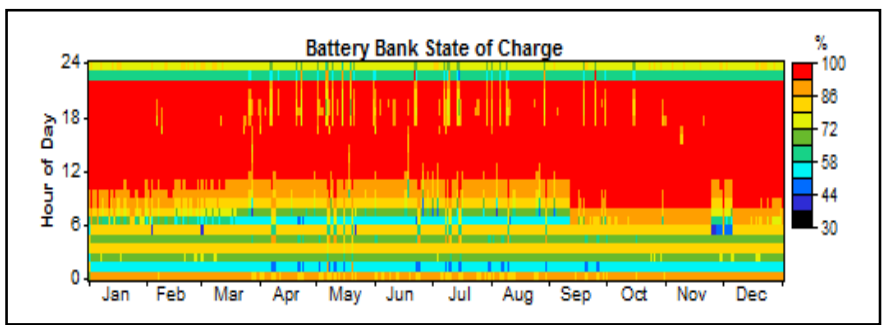

Figure 13: the battery bank state of charge

\section{CONCLUSIONS}

This paper presents design and modelling methodology to define hosting capacity of Horizon Power's isolated network of the town of Carnarvon, Western Australia to accommodate one hundred percentage integration of distributed PV installations. These include stability and reliability, network capacity, power quality and minimum loading of generating unit criteria. A mathematical model has been developed and implemented to visualise interaction among various system parameters. The model can be utilised as an analysis tool to define the hosting capacity and to assess system impacts due to integration of PV generation. The model utilisation has been demonstrated using study cases and performance monitoring of a selected network. 


\section{REFERENCES}

[1] S. Lewis, CEEM, and U. o. NSW, "APVA/CEEM(2012) Carnarvon: A Case Study of Increasing Level of PV Penetration inan Isloated Electricity Supply System, a report by the UNSW Centre for Energy and Environmental Markets for the Australian PV Association," p. 49, 2012.

[2] A. G. B. o. Meteorology, "Carnarvon, Western Australia Daily Weather Observations," 2014.

[3] J. Wood, "UltraBattery, Cloud Energy Storage for the Grid: Positioning Data Center and Telecommunication Backup Resources as Smart Grid Assets That Support," in Telecommunications Energy Conference 'Smart Power and Efficiency' (INTELEC), Proceedings of 2013 35th International, 2013, pp. 1-5.

[4] A. Swingler, "Photovoltaic String Inverters and Shade-Tolerant Maximum Power Point Tracking: Toward Optimal Harvest Efficiency and Maximum ROI," ed: Schneider Electric, 2010, p. 20.

[5] J. F. Manwell, J. G. McGowan, and B. H. Bailey, "Electrical/mechanical options for variable speed wind turbines," Solar Energy, vol. 46, pp. 41-51, // 1991.

[6] NREL. (2014). Homer Energy. Available: http://www.homerenergy.com/HOMER 2.html

[7] O. PSpice, "Advanced circuit simulation and analysis for analog and mixed-signal circuits," ed, 2014.

[8] M. Mathworks. (2014). An Introduction with Applications 2nd Edition.

[9] J. Wood, "Integrating Renewabls into the Grid: Applying UltraBattery Technology in MW Scale Energy Storage Solutions for Continuous Variability Management."

[10] L. Joon-Hwan, L. Seung-Hwan, and S. Seung-Ki, "Variable Speed Engine Generator with SuperCapacitor; Isolated Power Generation System and Fuel Efficiency," in Industry Applications Society Annual Meeting, 2008. IAS '08. IEEE, 2008, pp. 1-5.

[11] P. A. Stott and M. A. Mueller, "Modelling Fully Variable Speed Hybrid Wind Diesel Systems," in Universities Power Engineering Conference, 2006. UPEC '06. Proceedings of the 41st International, 2006, pp. 212-216.

[12] C. V. Nayar, S. J. Phillips, W. L. James, T. L. Pryor, and D. Remmer, "Novel wind/diesel/battery hybrid energy system," Solar Energy, vol. 51, pp. 65-78, 7// 1993. 